\title{
Further Improvements in Temperature Calculation During Cooling of Fish Packages
}

\author{
${ }^{1}$ F.A. Ansari, ${ }^{2}$ K.A. Abbas, ${ }^{3}$ J. Bakar, ${ }^{4}$ A.O. Ashraf, ${ }^{2}$ A.S. Mokhtar and ${ }^{2}$ S.M. Sapuan \\ ${ }^{1}$ Department of Mechanical Engineering, Aligarh Muslim University, Aligarh 202002, India \\ ${ }^{2}$ Faculty of Engineering, Universiti Putra Malaysia, 43400 Serdang, Selangor, Malaysia \\ ${ }^{3}$ Faculty of Food Science and Biotechnology, \\ Universiti Putra Malaysia, 43400 Serdang, Selangor, Malaysia \\ ${ }^{4}$ Faculty of Engineering, International Islamic University, Gombak, Kuala Lumpur, Malaysia
}

\begin{abstract}
In an earlier study, it was demonstrated that the empirical approach used to calculate the surface film conductance resulted into a higher value compared to those obtained from the other methods available in the literature. During further investigations, surface film conductance values were found to gradually decrease with a fall in temperature. When this non-linear variation was used to develop a correlation and it was used to calculate temperatures by the same empirical correlation, a remarkably excellent improvement in the calculated temperature resulted.
\end{abstract}

Keywords: Cooling, Fish, Surface Film Conductance, Temperature

\section{INTRODUCTION}

Literature review shows that heat and mass transfer analyses during cooling of food commodities are made by developing appropriate mathematical models and solving this model. This needs knowledge of thermophysical properties and system parameters. Significant thermophysical properties for most of the important food commodities are available in literature ${ }^{[1-}$ 8]. A number of analytical, graphical and numerical methods are available to make the heat transfer analysis $^{[9-19]}$ for temperature-time calculation or for prediction of cooling/processing time. For most of the heat transfer analyses, surface film conductance values predicted by the appropriate $\mathrm{Nu}-\mathrm{Re}$ correlation are used $^{[20-22]}$. Quite often, these values are found to give poor results. This is due to the fact that most of the foods have high water content. The evaporation from the surface of exposed food or even internal rearrangement of water molecules make the actual values higher than those predicted from the $\mathrm{Nu}-\mathrm{Re}$ correlation. The present investigation is towards thoroughly studying this phenomenon. It is a part of an ongoing research project regarding the quality measurement in cold preserved fresh water fish. Fish flesh of uniform thickness was put between two copper sheets and four faces were insulated to allow one dimensional heat transfer. These were then cooled in a chilled air duct maintained at a constant temperature of $1{ }^{\circ} \mathrm{C}$. Transient temperature-time records were used to predict surface film conductance values of the empirical correlation of the first author ${ }^{[21,22]}$. During the investigations it was found that surface film conductance decreased gradually with a reduction in temperature. The first author and his co-workers during similar investigations on fruits and vegetables observed similar trends. They had regressed the variation in the surface film conductance to obtain linear correlation. It was reported by ${ }^{[23]}$, that when this linear correlation was used to solve the heat conduction equation, an overall agreement was observed between the computed and measured temperature variations. In the present work, this variation has been refined and a non-linear correlation is used. During repeated investigations, it has been observed to give an excellent improvement of calculating temperatures. It has also been demonstrated that with the refined correlation of surface film conductance, the first author's empirical approach yields temperatures, which are superior to those calculated by the finite difference method.

The formulae used: Empirical correlation was developed and reported by the first author and his coworkers $^{[21-23]}$, which can calculate the surface film conductance from temperature time records. It is given as follows:

$$
\mathrm{Bi}=\left[\frac{\mathrm{d} . \mathrm{A}}{\mathrm{c} . \mathrm{Fo}-\mathrm{A}}\right]^{\frac{1}{\mathrm{e}}}
$$

Where:

$A=a+b \cdot \ln \left(\frac{1}{X+0.2}\right)-\ln U$

The constants a, b, c, d and e in the equations (1) and (2) are $-0.0422,0.16745,2.4674,2.240$ and 2.240 respectively for slab shape.

The above correlation can also be used to calculate temperature variations if the properties and system parameters are known. Temperature is given as: 
$\mathrm{U}=\exp (\mathrm{Y})(3)$

Where:

$$
\mathrm{Y}=\mathrm{a}+\mathrm{b} \cdot \ln \left(\frac{1}{\mathrm{X}+0.2}\right)-\frac{\mathrm{c} \cdot \mathrm{Bi}^{\mathrm{e}} \cdot \mathrm{Fo}}{\mathrm{Bi}^{\mathrm{e}}+\mathrm{d}}
$$

The conventional method, which has been used till date is to write the mathematical model along with initial and boundary conditions. This mathematical model is then solved by analytical, graphical or numerical method to estimate temperature time variations. For isotropic rectangular shaped solid, initially at a uniform temperature and exposed to symmetric cooling on both sides, the governing heat conduction equation, initial condition, center boundary condition and surface boundary condition for pure convection are written by the following system of normalized equations ${ }^{[18,21,23]}$ :

$$
\begin{aligned}
& \frac{\partial^{2} U}{\partial X^{2}}=\frac{\partial U}{\partial F_{0}} \text { for } F o \geq 0.4 \text { and } 0 \leq X \leq 1 \\
& U=1 \text { for } F o=00 \leq X \leq 1 \\
& \frac{\partial U}{\partial X}=0 \text { for Fo }>0 \quad X=0
\end{aligned}
$$

$$
\frac{\partial U}{\partial X}=\text { Bi.U for Fo }>0 \quad X=1
$$

Since the samples were covered and no evaporation happened, the case has been considered as pure conviction.

\section{RESULTS AND DISCUSSION}

Experimental and theoretical investigations were carried out on a number of slab shaped samples of freshwater Malaysian Patin fish. The experimental set up, sample preparation and measurement technique are explained in an earlier study ${ }^{[24]}$. Each fish sample was $2.54 \mathrm{~cm}$ thick. The properties used for calculations are as given below:

$\mathrm{K}=0.5294 \mathrm{~W} / \mathrm{m} . \mathrm{K}$ and $\alpha=0.134 \mathrm{~mm}^{2} / \mathrm{s}$.

$\mathrm{K}$ value was calculated empirically from the measured water content of fish and $\alpha$ value was that found out experimentally during the present investigation and reported elsewhere. These thermophysical properties were used to determine the surface film conductance for each fish sample through the transient temperature-time measurements at four equidistant points inside the sample by Equations (1) and (2). An iterative technique was used by comparing the calculated temperature at each time step using Equations (3) and (4) and the measured temperature. All the calculations were made for $\mathrm{Fo} \geq 0.2$; for which these equations are reported to be valid ${ }^{[21-23]}$. The surface film conductance values were found to be almost $100 \%$ more than those calculated from the $\mathrm{Nu}-\mathrm{Re}$ correlations. It was found to decrease gradually with a fall in the product temperature. This variation was found to be consistently non-linear, as shown in Fig. 1. The least square analysis yielded the following correlation between surface film conductance and local temperature:

$\mathrm{h}=\frac{65.7339-3.76056 \mathrm{~T}}{1.0-0.08484 \mathrm{~T}+0.001535445 \mathrm{~T}^{2}}$

Variable surface film conductance given by Equation (9) and the measured thermophysical properties were used to compute temperature distributions in the fish flesh sample. First, the empirical approach of the first author, as given by Equations (3) and (4) was used. Temperatures were also calculated by numerically solving the mathematical model defined by Equations (5) to (8) using the optimized explicit finite difference scheme of the first author $^{[25]}$. Calculation results for all the fish samples were graphically analyzed and compared with the measurement results. Plots for one sample at four equidistant points of a sample are shown in Fig. 2-5.

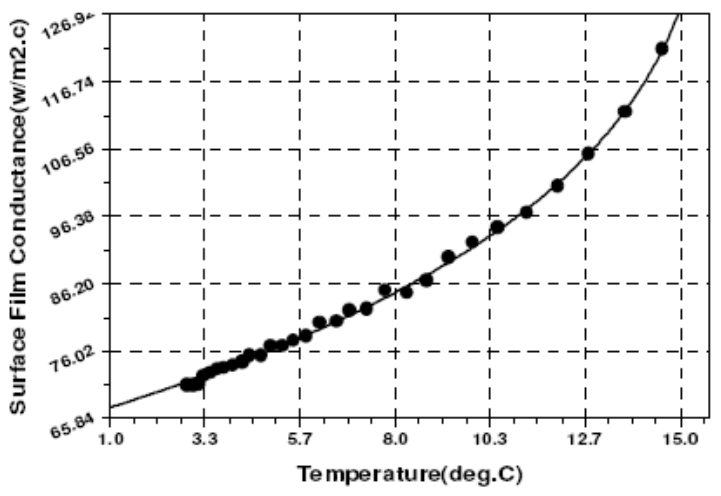

Fig. 1: Surface film conductance versus temperature curve

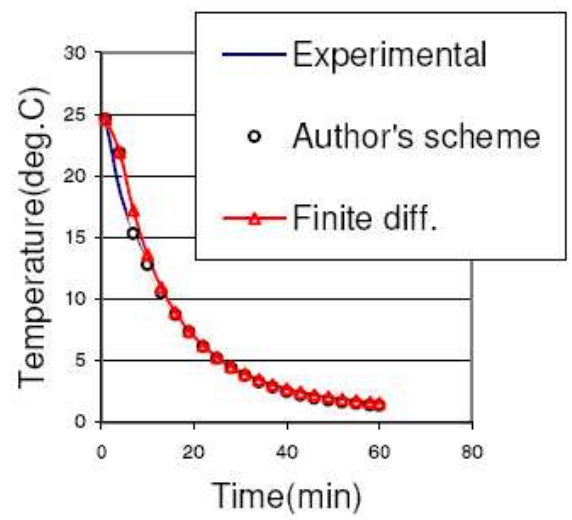

Fig. 2: Validity of Authors' Scheme in Comparison with the Experimental and Finite Difference Results at $\mathrm{X}=0.0$ (center) 


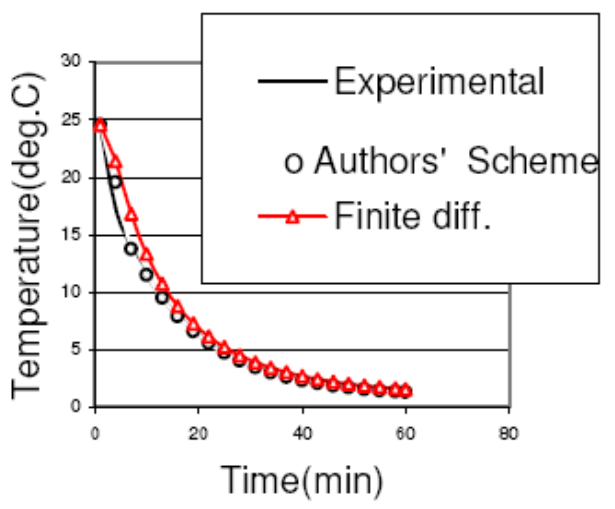

Fig. 3: Validity of Authors' Scheme in Comparison with Experimental and Finite Difference Results at $\mathrm{X}=0.2$

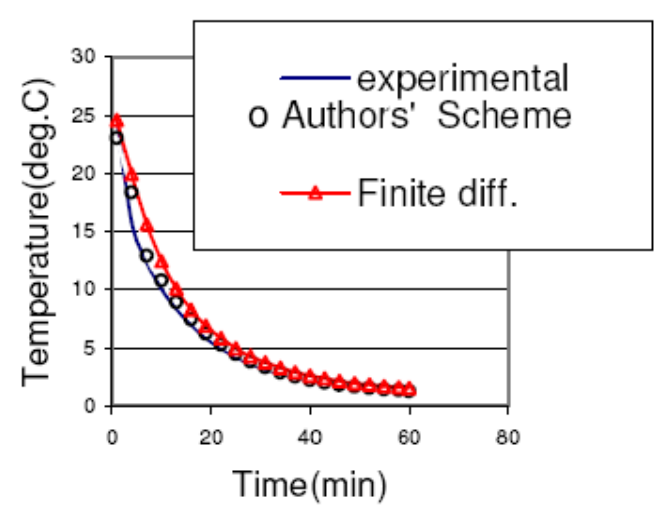

Fig. 4: Validity of Authors' Scheme in Comparison with Experimental and Finite Difference Results at $\mathrm{X}=0.4$

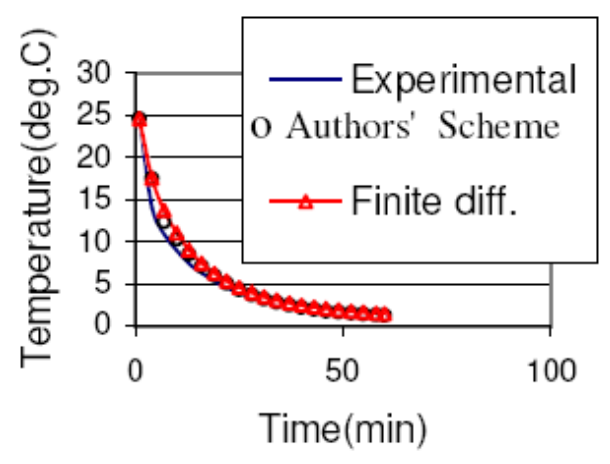

Fig. 5: Validity of Authors' Scheme in Comparison with Experimental and Finite Difference Results at $\mathrm{X}=0.6$

Temperatures by both the methods were almost coinciding with measured results after some initial cooling time. Even in the beginning, a reasonably good agreement was consistently observed.
Table 1: Mean root square errors

\begin{tabular}{lllll}
\hline Locations & $\mathrm{X} 0$ & $\mathrm{X} 1$ & $\mathrm{X} 2$ & $\mathrm{X} 3$ \\
\hline Empirical method & 0.0045 & 0.0056 & 0.0427 & 0.077 \\
Finite difference & 0.046 & 0.103 & 0.139 & 0.124 \\
Method & & & & \\
\hline
\end{tabular}

For all the samples, the temperatures calculated from the empirical equation were comparatively still better. At all the locations the empirically calculated temperatures were found coinciding with the measured values. Figure 5 shows calculated and measured temperatures at $X=0.6$; the point nearest to the surface. At this point there is relatively more deviation between the calculated and measured temperatures up to almost initial 30 minutes of cooling. But, even in this case, the empirically calculated temperatures exhibit better agreement as compared to those calculated by finite difference method.

Least square analysis was made for both the calculated temperatures by using the following equation:

$S_{n}=\frac{1}{m} \sqrt{\sum_{i=1}^{m}\left(T_{M}-T_{n}\right)^{2}}$

$T_{M}$ is the measured value of temperature. Subscript $\mathrm{n}$ is substituted by either $\mathrm{E}$, representing the empirically calculated values or by $\mathrm{F}$, which denotes the results obtained by finite difference method. The constant $\mathrm{m}$ represents the number of data points and $S_{n}$ is the arithmetic mean of root square errors.

The results by the empirical method were found to give consistently better agreements for all the samples investigated (Table 1).

In case of the empirical approach, root mean square error is consistently better than that in the finite difference method. It establishes the reliability of the empirical approach, which is simple but highly accurate. Therefore, the present extremely simple and highly reliable calculation scheme may be recommended to make heat transfer analysis for food items.

\section{CONCLUSION}

With known thermophysical properties, transient temperature-time records at a location midway between the center and the surface and the empirical correlation of the first author can be used to find out iteratively surface film conductance at each temperature step. Regression analysis may be used to find out the best-fit curve of surface film conductance as a function of temperature. This relationship can be used along with the same empirical correlation to predict temperature variation at any location in the food flesh. 


\section{ACKNOWLEDGEMENT}

The present work has been funded through the internal research funding of the Multimedia University (MMU), Malaysia, which is thankfully acknowledged. The authors also acknowledge the experimental and computational facilities provided by the MMU. During the course of work, the teaching and technical staff of the Faculty of Food Sciences and Biotechnology, Universiti Putra Malaysia has been kind enough to provide help and encouragement. All their encouragement and help is thankfully acknowledged.

\section{Nomenclature:}

Bi: $\quad$ Biot number $\left(=\mathrm{h} \cdot \mathrm{x}_{0} / \mathrm{k}\right)$

$c_{\mathrm{p}}$ : Specific heat of fish $(\mathrm{J} / \mathrm{kg} \cdot \mathrm{K})$

Fo: Fourier number $\left(\alpha . t / x^{2}\right)$

$\mathrm{H}: \quad$ Surface film conductance $\left(\mathrm{W} / \mathrm{m}^{2} . \mathrm{K}\right)$

K: Thermal conductivity (W/m.K)

M: Shape index; 0 for infinite slab, 1 for infinite cylinder and 2 for sphere

$\mathrm{Nu}$ : Nusselt number $(=\mathrm{h} . \mathrm{x} 0 /$ kair $)$

Pr: Prandtl number

Re: Reynolds number $\left(=\mathrm{v} \cdot \mathrm{x}_{0} / \gamma\right)$

T: $\quad$ Temperature $\left({ }^{\circ} \mathrm{C}\right)$

T: Time (s)

$\mathrm{U}: \quad$ Normalized temperature $\left[=\left(\mathrm{T}-\mathrm{T}_{\mathrm{cm}}\right) /\left(\mathrm{T}_{\mathrm{i}}-\mathrm{T}_{\mathrm{cm}}\right)\right]$

$\mathrm{W}$ : Water content, \% (on wet mass basis)

$\mathrm{X}$ : Normalized space coordinates $\left(=\mathrm{x} / \mathrm{x}_{0}\right)$

$\mathrm{X}$ : Distance from central plane, central axis or center (m)

$\mathrm{x}_{0}: \quad$ Half thickness or radius $(\mathrm{m})$

\section{Greek letters:}

$\alpha$ : Thermal diffusivity of $\left(\mathrm{m}^{2} / \mathrm{s}\right)$

$\gamma$ : Kinematics viscosity of air at mean temperature $\left(\mathrm{m}^{2} / \mathrm{s}\right)$

\section{Subscripts and Superscripts:}

$\mathrm{Cm}$ : Cooling medium

i: Initial

\section{REFERENCES}

1. Woolrich, W.R., 1933. The Latent Heat of Foodstuffs. University of Tennessee Engineering Experiment Station Bulletin, No. 11.

2. Tressler, D.K., W. B. Van Arsdel. And M. J. Copley, 1968. The Freezing Preservation of Food. Westport: AVI Publishing Co. Inc.

3. Qasho, M.S., R. I. Vachan and Y. S. Toulokian, 1972. Thermal conductivity of foods. ASHRAE Transactions 78: 78.
4. Gaffney, J.J., C. D. Baird and W. D. Eshleman, 1980. Review and analysis of transient method for determination of fruits and vegetables. ASHRAE Transactions 86: 261.

5. Mohsenin, N. N., 1980. Thermal Properties of Food and Agricultural Materials, New York: Gordon and Breach Science Publishers.

6. Aquirre, R.L, C.D. Baird, J. J. Gaffney, K. V. Chau and R. Mathus, 1981. Determination of specific heat by means of boiling liquid. Paper No. 813037, Summer Meeting, ASAE, Orlando, Florida, U.S.A.

7. ASHRAE, 1977. ASHRAE Handbook of Fundamentals. Atlanta, G.A.: ASHRAE Inc.

8. ASHRAE, 1981. ASHRAE Handbook of Fundamentals. Atlanta, G.A. : ASHRAE Inc.

9. Gurnie, H.P. and L. Lurie, 1923. Charts estimating temperature distribution in heating or cooling solid shapes. Industrial and Engineering Chemistry. 15: 1170.

10. Heisler M.P., 1947. Temperature charts for induction and constant temperature heating. ASME Transaction. 1947: 277.

11. Pflug, I.J. and I. J. Kopelman, 1966. Correlating and predicting transient heat transfer rates in food products. Bull. Int. J. Refrigeration Annexes 2: 89.

12. Pflug, I.J., J. L. Blasdell and I. J. Kopelman, 1965. Developing temperature-time curves for objects that can be approximated by a sphere, infinite plate or infinite cylinder. ASHRAE Transaction 7: 238.

13. Bennett A.H., W. G. Chace and R. H. Cubbedge, 1969. Heat transfer properties and characteristics of Appalachian area red delicious apples. ASHRAE Transaction 75:133.

14. ASHRAE, 1971. ASHRAE Guide, Data Book Applications. Atlanta, G. A.: ASHRAE Inc.

15. ASHRAE, 1974. ASHRAE Handbook of Fundamentals. Atlanta, G. A.: ASHRAE Inc.

16. Hayakawa, K.I., 1972. Estimation temperatures of foods during various heating or cooling treatments. ASHRAE J. 14: 65

17. Baird, C.D. and J.J. Gaffney, 1976. A numerical procedure for calculating heat transfer in bulk loads of fruits and vegetables. ASHRAE Transactions 82: $525-40$.

18. Ansari, F.A., 1984. Heat and Mass Transfer Analysis in Cold Preservation of Food. Ph.D. Thesis, Univ. Roorkee, Roorkee, India.

19. Dincer, I., 1993. An exact heat transfer analysis of spherical products subjected to air cooling. Int. J. Energy Res. 17: 9-18.

20. Chapman A.J., 1984. Heat Transfer. New York: The Macmillan Publishing Co.

21. Ansari, F.A., 1986. An empirical method of measuring diffusivity and surface film conductance. Transaction of ASAE 29: 1492-1497. 
22. Ansari, F.A., A. Mughis and A. Mukhtar, 1987. Measurement of thermophysical properties of mashed potato, Lebensm.-Wiss. U- Technol., Switzerland 200: 267-270.

23. Ansari, F.A. and S.Y. Khan, 1999. Application concept of variable effective surface film conductance for simultaneous heat and mass transfer analysis during air blast cooling of food. Energy Conversion and Management 40: 567-74.
24. Ansari, F.A., M.A. Wan and K.A. Abbas, 2002. An improved scheme for temperature calculations in Food. Energy Conversion and Management 44: 2373-2382.

25. Ansari, F. A., 1999. Finite difference solution of heat and mass transfer problems related to precooling of food. Energy Conversion and Management 40: 795-802. 